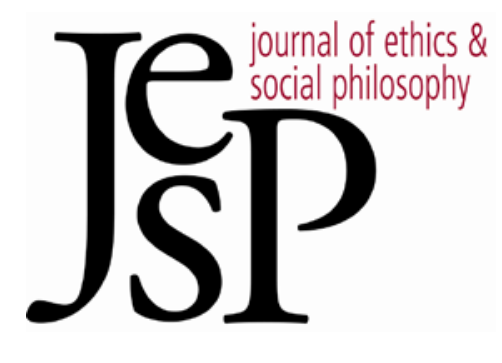

\title{
AgAinst InSTITUTIONAL LUCK EgaLiTARIANISM
}

\author{
BY REKHA NATH
}




\title{
Against Institutional Luck Egalitarianism
}

\author{
Rekha Nath
}

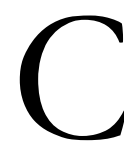

ENTRAL TO LUCK EGALITARIANISM is the idea that people should not fare differently from one another based solely on differences in luck. To demonstrate the intuitive appeal of this idea, luck egalitarians point to examples of luck-based inequalities that are widely regarded as unjust - for instance, disparities in individuals' opportunities for economic advancement based on contingent factors such as skin color or gender. Yet, upon reflection, the intuitive appeal of the idea that inequalities due to differences in luck are for that reason unjust appears questionable. To illustrate, it does not seem an injustice that beautiful people are asked out on more dates than the homely, nor that clumsier individuals might be indefinitely relegated to the bench while those with innate athletic prowess shine on the football field.

How can it be that (1) the unjust nature of certain inequalities seems to be explained by their source in luck, while (2) not all inequalities that stem from luck seem unjust? Kok-Chor Tan $(2008 ; 2011 ; 2012)$ advances a theory of egalitarian justice that answers that question. His theory has two central commitments: it has an institutional focus and it is luck egalitarian. Tan calls his theory institutional luck egalitarianism (ILE). Based on its institutional focus, ILE implies that luck-based inequalities are unjust if and only if they are produced by institutions. Due to its luck egalitarian character, ILE implies that institutional arrangements that impact individuals' lives violate the demands of distributive justice if and only if they favor some over others based on luck.

Tan thinks ILE can explain the unjust nature of those luck-based inequalities that seem intuitively troubling, thereby accommodating (1). The explanation is that the luck-based inequalities that seem intuitively unjust turn out to have an institutional cause. He also thinks ILE can accommodate (2), the intuition that not all luck-based inequalities are unjust. The explanation is that the luck-based inequalities that do not seem intuitively unjust turn out not to have an institutional cause.

In accounting for both (1) and (2), Tan (2008: 667-68; 2012: 90, 97-99, 126-29 and 142-44) takes his theory to compare favorably to two rival theories of egalitarian justice - democratic equality and trans-institutional versions of luck egalitarianism (TILE). ${ }^{1}$ Each of these other theories, he argues, accounts for either (1) or (2) but does so at the cost of sacrificing the other. Democratic equality fails to account for (1) because it implies that the demands of egalitarian justice are not foundationally concerned with counteracting luck-based inequalities. And TILE fails to accommodate (2) because it

1 Tan (2012: 97 and 128) regards Anderson (1999), Freeman (2007) and Rawls (2001) as proponents of democratic equality, and Arneson (2000) as a proponent of TILE. 
implies that all luck-based inequalities that can be addressed, even those that are not produced by institutions, are unjust.

I will argue that ILE does not account for both (1) and (2). ${ }^{2}$ That ILE gives the impression of doing so derives from an ambiguity concerning what it means for an inequality to qualify as institutionally influenced. On some conceptions of institutional influence, ILE accounts for (1) but not (2). On other conceptions, ILE accounts for (2) but not (1). It is doubtful that there is any tenable conception that enables ILE to avoid this dilemma.

The paper proceeds as follows. In section 1, I explain how, according to Tan, ILE's luck-egalitarian character and institutional focus enable the theory to account for both (1) and (2). In section 2, I set out the details of the dilemma that ILE faces. In section 3, I develop and reject a response suggested by some of Tan's remarks. In section 4, I conclude by explaining why the dilemma exposes serious shortcomings of ILE and what this implies for the prospects of ILE in relation to competing theories.

\section{The Range on ILE}

Take the range specified by a theory of egalitarian justice to include those, and only those, inequalities that count as unjust on that theory. ${ }^{3}$ Accounting for (1) and (2) is a matter of which inequalities are in the range on ILE and why. So, let us turn to Tan's explanation of why particular inequalities are in the range on ILE.

According to Tan, what individuals owe to one another as a matter of distributive justice is informed by the relationships in which they stand. He takes relations of impact, in which individuals affect one another through institutional arrangements that regulate their interaction, to give rise to demands of distributive justice. Those who are affected by an institution are owed justification for the character of its impact (2012: 158-59).

In Tan's view, that justification should be luck egalitarian. Luck egalitarians, as Tan characterizes the position, endorse the luck/choice principle, on which the relative distributive shares individuals are accorded ought to be "fundamentally choice-sensitive but luck-insensitive" (2008: 666; see also 2012: 88-91 and 108). This means, on the one hand, that individuals should not fare differently from one another simply due to differences in luck - that

2 I do not take a stance in this paper on whether a plausible theory of egalitarian justice ought to account for both (1) and (2).

3 The range encompasses two other dimensions of a theory of egalitarian justice: (1) its scope - between whom demands of egalitarian justice arise, and (2) its currency - what should be equalized, for instance, resources, welfare or something else. I follow Tan (2012: 15-16 and 105-6) in discussing ILE in a general form that does not presume a commitment to any particular currency. 
is, contingent factors over which they have no control. On the other hand, inequalities that can be traced to choice rather than to luck are acceptable. ${ }^{4}$

So, in institutional contexts, in which demands of distributive justice arise, what individuals are owed is determined by the luck/choice principle on ILE. This principle implies that it is unjust for an institutional arrangement to favor some of the individuals whose lives it impacts over others based on matters of luck. This explanation of how institutions activate luckegalitarian demands specifies what is in the range on ILE: if an inequality is luck-based and produced by an institution, then it is in the range on this theory.

Moreover, on ILE, only inequalities that are luck-based and have an institutional input qualify as unjust and thus fall in the range. That is, on Tan's view, considerations of justice only arise in the presence of institutions that affect people's lives, while "natural facts ... are neither just nor unjust in themselves" (2012: 153-54). What accounts for the injustice of particular morally arbitrary inequalities, for Tan, is "the fact that existing social and political institutions and practices have converted ... natural and contingent facts into social advantages and disadvantages for people" (2012: 153). So, on this theory, all that individuals are owed as a matter of distributive justice is that institutions do not discriminate based on luck in determining their relative shares.

Why does Tan take the luck/choice principle to exclusively concern how individuals are affected by institutional arrangements? ${ }^{5}$ An alternative is that other instances of impact - such as when individuals affect one another independently of institutional arrangements - would also activate the luck/choice principle. Consider an example to see what this alternative would entail. Suppose a parent spends hours each evening helping his daughter finetune her tennis strokes. Due to all this help, his child outshines her school teammates on the court. Her advantage over the others is due to luck: the other kids are not so fortunate to have parents with the time or the skills to provide such extra coaching. If the luck/choice principle were to apply to an individual's every action that affects others, then the morally arbitrary inequality that the father produces in this case would be unjust. To remedy this injustice, he might extend an invitation to all interested kids who wish to join

${ }^{4}$ On luck egalitarianism, satisfaction of luck-insensitivity in individuals' relative shares entails satisfaction of choice-sensitivity (and vice versa). Whether there is a plausible means by which to determine the source of an inequality, in luck or in choice, has been subject to considerable debate. For the sake of argument, I assume in what follows that there is indeed such a means of doing so. In any case, this is not an issue that uniquely confronts Tan but one that faces all luck egalitarians. See Tan (2008: 668-69; 2012: 91-97) on the luck/choice distinction.

5 Although, on ILE, the luck/choice principle only directly concerns the design of institutions, the theory also implies that individuals have obligations to one another: those who partake in an institutional arrangement have mutual, institutionally mediated obligations to ensure that the rules of that arrangement do not discriminate based on luck (2012: 19-21). 
these coaching sessions instead of devoting disproportionate attention to his own daughter.

In Tan's view, inequalities of the sort produced by the father's exclusive coaching of his daughter do not qualify as unjust. And he rejects the alternative that implies otherwise. He explains that if the luck/choice principle were to regulate individuals' actions, then their abilities to engage in valuable personal pursuits stand to be significantly constrained (2012: 19-34 and 192-93). This would be problematic since some personal endeavors, such as a parent's focus on improving only his daughter's tennis skills, seem legitimate in spite of generating morally arbitrary inequalities. ILE accommodates this intuition. As Tan emphasizes, on the basis of its exclusive focus on institutions, his theory "allows for a way of reconciling the impersonal demands of egalitarian justice and the pursuits of personal ends and commitments" (2012: 50). ILE does this because it mandates that, on the one hand, the institutional arrangements that fundamentally shape individuals' lives must refrain from discriminating based on luck and, on the other hand, space be preserved for individuals to engage in valuable personal endeavors within the institutional parameters that are set. ${ }^{6}$

Furthermore, Tan takes distributive justice to concern only "how persons fare in relation to each other above a threshold of sufficiency" (2012: 100). So, below this threshold, considerations of distributive justice do not arise in his view. 7 Above this threshold, he takes the luck/choice principle to have primacy in determining what individuals are owed as a matter of distributive justice. What that means is that the luck/choice principle alone provides a foundational basis for determining individuals' distributive entitlements on ILE (2008: 667, 679 and 688-89; 2012: 125-26 and 141). Other normative considerations do not play a role in determining what counts as a just share.

So, on ILE, for an inequality to be in the range, it is necessary and sufficient that it be luck-based and institutionally influenced. Tan takes the range on his theory to be neither implausibly narrow nor implausibly broad: that is, it includes intuitively troubling inequalities and excludes inequalities that do not intuitively seem to be a matter of justice.

To see why Tan thinks the range on ILE is not implausibly narrow, consider a case he discusses (2012: 162-63). Two communities live along different parts of a river in relative isolation from one another. Both depend on

${ }^{6}$ For a morally arbitrary inequality to be in the range on Tan's theory it must have an institutional input. However, his argument for an exclusive focus on institutions (which I have just summarized) does not address the issue of range. Instead, it addresses the issue of the site of justice, in particular, whether principles of justice directly apply only to institutions, as Tan argues, or also to individuals. These two issues, site and range, are independent: an institutional site does not imply an institutional range, and an institutional range does not imply an institutional site. I will address the plausibility of restricting the range to inequalities with an institutional input in the following section.

7 However, in such cases, Tan (2012: 100-102) thinks that moral considerations distinct from distributive justice may come into play. In this way, ILE is compatible with a humanitarian principle mandating assistance for individuals suffering basic-needs deprivations. 
the river for fish. One day, the community that is settled upstream in relation to the other places a net across the river. Doing so enables members of the upstream community to catch more fish than they could before, while it worsens members of the downstream community's access to the same (although their ability to meet their basic needs is not compromised).

This might seem to be a case in which there are no institutional connections between the two societies yet in which the morally arbitrary inequality between them is troubling. However, Tan explains, he understands "institutions" broadly, taking this term to encompass legally regulated, political and economic institutional arrangements as well as social practices, norms and expectations that publicly regulate the basis upon which individuals interact and affect each other's lives (2011: 411; 2012: 35-38 and 157-58).8 Consequently, because the upstream community puts into place an arrangement that affects those in the downstream community, ILE implies that the latter are owed a justification for how they are affected by it (2012: 162-63). The upstream community's decision to place the net across the river is unjust insofar as it privileges some individuals over others based on the contingent matter of where along the river they happen to live.

Still, it might seem that some inequalities due solely to natural misfortune are unjust but, implausibly, would be excluded from the range on ILE. Take the case of a society that lacks a public education system in which the life prospects of a child who happens to be born to impoverished, deadbeat parents who do not invest in her education will be bleak compared to a child who has wealthy, conscientious parents. It might appear that ILE cannot account for the unjust nature of this inequality since a society does not control what sort of parents one happens to have. However, Tan (2008: 672-73) thinks that an institutional explanation for this disadvantage can be found. Usually, he notes, a child's chances of economic success are not merely a function of unluckily having poor parents, but rather are significantly influenced by her society's institutions.

Analogously, it may initially seem that ILE would not count as unjust the disadvantaged position of those who have suffered great losses caused by a hurricane or the relative hardships faced by individuals born with physical disabilities. Again, Tan (2008: 681) points out how the particular design of a society's institutions can significantly affect the extent to which natural disas-

${ }^{8}$ Given this broad construal of institutions as well as the existence of numerous norms regulating interaction across state borders, Tan (2012: 153-59 and 170-71) thinks that ILE can account for the intuitively unjust nature of many global inequalities. Moreover, he takes ILE to support a more plausible moral assessment of global inequality than democratic equality does. On democratic equality, as Tan characterizes the position, there must be a commitment to democratic reciprocity on a global level for cross-border egalitarian demands to be activated. Consequently, he takes democratic equality to either imply that global inequalities are not unjust or give a less plausible explanation than ILE does of why they are unjust (2008: 687-90; 2011: 398 and 412; 2012: 135-36, 144-45, 157-58, 163-65 and 187). In the latter case, he suggests that democratic equality would fail to capture why certain global inequalities seem intuitively troubling: namely, that they result from luck-based discrimination. 
ter victims are disadvantaged. And insofar as the design of a society's public spaces is primarily geared toward accommodating the able bodied, with stairs and high curbs that are incompatible with the mobility needs of individuals in wheelchairs, institutions can be shown to play a role in turning a natural contingency into a disadvantage (2008: 673, n. 16). Based on such observations, Tan suggests that "given the wide and interconnecting reach of social institutions, many of the typical cases of social and economic inequalities that exercise egalitarians can be revealed to have an underlying institutional explanation" (2008: 673). So, that is why he thinks the range on ILE is not implausibly narrow.

Tan also maintains that the range on ILE is not implausibly broad. Recall the case of homely individuals who get asked out on dates by desirable suitors less frequently than their better-looking peers. Suppose that the beautiful are lavished with gifts, taken to fine restaurants and the opera, and whisked away by their suitors on holidays to exotic places like Tahiti, while the ugly miss out on these things. ${ }^{9}$ On TILE, this inequality is unjust and should be remedied by such measures as publicly subsidized cosmetic surgery or monetary compensation for the ugly. However, to the extent that such inequalities do not result from a discriminatory institutional arrangement, Tan (2008: 126-29) emphasizes that ILE avoids this absurd implication.

He describes other examples of inequalities that would be excluded from the range on his theory (2012: 142-43). Individuals who happen to be slightly shortsighted or flat-footed, but whose inflictions are not so bad as to raise humanitarian concerns, would not be owed social compensation for small burdens associated with their conditions. Again, such parties do not have a claim on society to the extent that their afflictions are not brought about by institutions. Tan finds this result plausible, noting that it does not seem unreasonable that individuals be expected to personally bear minor costs associated with these conditions, for instance, by paying for eyeglasses or arch supports. In this way, he takes ILE to accommodate the intuition that not all inequalities that stem from luck seem unjust.

\section{A Dilemma for ILE}

That ILE has a plausible range is for Tan a principal virtue of his theory. But is he correct that its range is plausible? That is, does the range on ILE in fact accommodate our intuitions about which inequalities are unjust? The answer depends on whether ILE actually upholds Tan's verdicts on the sorts of cases he discusses - the river, education, hurricane and disability cases, on the one hand, and the ugliness, shortsightedness and flat-footedness cases, on

9 Tan does not specify which relative disadvantages endured by the ugly would be excluded from the range on ILE. However, this illustration seems to capture the sorts of inequalities he has in mind based on remarks he makes (2008: 671-72 and 680-83; 2011: 403; 2012: 76-79 and 126-27). 
the other. The capacity of the theory to support these and relevantly similar verdicts may be seen as a litmus test for assessing Tan's claim that ILE implies a range that is neither implausibly narrow nor broad. To imply a plausible range, ILE need not yield the desired verdicts in every conceivable case. But its verdicts must generally cohere with the relevant intuitions, or Tan's defense of the theory on this count is undermined..$^{10}$

To determine whether ILE does actually support the desired verdicts, we need to be able to tell which morally arbitrary inequalities are brought about by institutions. That is, we need to know when it is the case that institutions turn natural contingencies into social (dis)advantages for some individuals such that the ensuing luck-based inequalities qualify as institutionally influenced. ${ }^{11}$ Despite the centrality of the concept of institutional influence to his theory, Tan never spells out precisely what it means for an institution to produce an inequality. This is a serious omission.

I will address this omission by considering different conceptions of institutional influence that ILE might employ. I will argue, however, than none suffices for his purposes. There appears to be no conception of institutional influence on which the range on ILE avoids being implausibly narrow or implausibly broad by Tan's own lights of what counts as plausible. My argument takes the form of a dilemma and can be summarized as follows:

1. If, on a certain conception, $C$, of institutional influence, ILE excludes from the range the sorts of inequalities that Tan thinks it should exclude, then the range will be implausibly narrow: for the range will also exclude inequalities that Tan thinks it should include.

2. If, on a certain conception, C, of institutional influence, ILE includes in the range the sorts of inequalities that Tan thinks it should include, then the range will be implausibly broad: for the range will also include inequalities that Tan thinks it should exclude.

3. Therefore, on any conception of institutional influence, the range on ILE will be (by Tan's own lights of what counts as plausible) either implausibly narrow or implausibly broad.

Of course, I cannot consider all possible conceptions of institutional influence that ILE might employ. But I will consider what seem to be the most likely candidates, each of which is suggested by some of Tan's comments on the matter. Each implies that the range on ILE is implausible (again, by Tan's own lights). If there is a different conception that would enable the theory to avoid that problematic implication, it is far from clear what that would be.

In the river case discussed above, Tan emphasizes that the upstream community's intervention creates an unjust inequality: the intervention causes

10 Tan (2012: 142-44) appears to hold his theory to this standard.

11 Tan (2008: 671-75, 680-81 and 689) variously refers to (dis)advantages with an "institutional input," instances in which institutions "convert" or "turn" matters of luck into social (dis)advantages and in which they "generate" or "confer" (dis)advantage. 
members of the downstream community to become worse off (relative to members of the upstream community) than they were before. This suggests that the notion of institutional influence ILE relies upon may be understood as follows. An institutional arrangement produces an inequality if and only if it causes some individuals to become worse off (relative to others) than they were prior to being impacted by that institutional arrangement (relative to those others). Call this conception of institutional influence C1, and call ILE on C1 ILE-C1.12

On reflection, however, the range on ILE-C1 turns out to be implausibly narrow. This is because on ILE-C1 an institutional arrangement may justifiably treat parties differently based on luck if those who are accorded a lesser share than others have happened to fare worse than the relevant others all along. Recall Tan's verdict that a society treats disabled citizens unjustly in failing to accommodate them adequately in public spaces. Now consider two variants of this case. In Variant One, a state-funded renovation project demolishes handicapped-accessible public spaces and replaces them with areas that do not accommodate wheelchairs. Due to this renovation, there is now a significant discrepancy in access to public spaces between the disabled and the able bodied as compared to before. In Variant Two, take a society that has never adopted measures to accommodate the disabled in public spaces. Again, the society renovates its public spaces, and this renovation leaves unchanged the handicapped-inaccessible status of those spaces. So, unlike in Variant One, the disabled fare no worse relative to able-bodied citizens than they did before the renovations. ${ }^{13}$

ILE-C1 implies that in Variant One, but not in Variant Two, the relative disadvantage of the disabled citizens is institutionally influenced and thus unjust. In Variant One, the institutional intervention results in increasing the morally arbitrary disparity in access to public spaces between disabled and able-bodied citizens. In Variant Two, however, the institutional intervention does not increase the disparity that was already in place. So, in Variant Two, the inequality does not qualify as unjust on C1. Tan would not accept that result. The difference between Variant One and Variant Two does not seem relevant to determining the demands of justice. In both cases, he would maintain that the disabled are treated unjustly. So, C1 does not seem to be the conception of institutional influence that he has in mind.

\footnotetext{
12 Besides cases in which institutional arrangements worsen a person's relative position compared to how she fared before the imposition of those arrangements, this conception can be broadened to include cases in which institutional arrangements worsen a person's relative position compared to how she would have fared in the absence of those arrangements. With this addition, ILE-C1 can account for the injustice of inequalities in cases of longstanding, discriminatory institutional arrangements in which a historical benchmark of how parties fared before their subjection to those arrangements would have no referent.

13 We might plausibly assume that individuals who happen to be disabled would tend to face greater hardships than able-bodied persons in the absence of any social institutions at all.
} 
Consider why the judgment yielded by ILE-CI in Variant Two seems misguided. In this case, society regulates the design of public spaces, and it thereby determines how its members will be able to make use of those areas. Because society plays this role of determining the character of public spaces, it seems that individuals are owed a justification for how they will be affected by its policies on this issue. From a luck-egalitarian standpoint, it seems that society should not discriminate based on morally arbitrary factors in determining how much citizens stand to benefit from its policies relative to one another, even if similar luck-based inequalities would obtain between the relevant individuals in the absence of the imposition of those policies. So, the fact that there were morally arbitrary inequalities prior to an institutional intervention does not seem to give a society license to preserve those preinstitutional inequalities through the policies that it adopts.

One might infer from this reasoning that whether an institutional arrangement is unjust turns on whether it treats some individuals more favorably than others based on contingent factors, regardless of how those individuals fared relative to one another in the past. In both variants of the case at hand, this implies that, given society's role in determining the design of public spaces, it owes to all citizens the enjoyment of luck-insensitive relative access to those spaces. These reflections suggest a conception of institutional influence that differs from C1: An institutional arrangement produces an inequality if and only if it regulates the distribution of some good, and it grants some individuals a lesser share than others of the given good. Call this conception $C 2$.

However, ILE-C2 appears to imply an implausibly narrow range, just as ILE-C1 does. Recall the case of a society with no public education system in which individuals born into poverty generally are not as well positioned as others to obtain desirable economic positions. Let us consider whether ILEC2 supports Tan's verdict that this inequality is unjust. On ILE-C2, for an inequality to be unjust it must result from an institutional arrangement that arbitrarily grants a greater distributive share to some individuals over others. But, in this case, it is not clear which aspect of the society's institutional arrangement can be criticized. The fact that some individuals have inferior opportunities for attaining an education does not seem traceable to any discriminatory institutional practice: there is no public system of education under which opportunities are unequal. It is the very absence of the social regulation of education that seems problematic. Yet if we cannot point to any way in which particular institutional policies arbitrarily favor some over others, then it looks as though this inequality fails to qualify as unjust on ILE-C2. This result suggests that Tan would reject C2.

In response, Tan might argue that owing to its failure to establish a system of universal education this society can be regarded as producing the disadvantages endured by those citizens who are deprived of a decent education. After all, that failure reflects an institutional decision made by society concerning which public goods it will and will not provide. This reasoning lends 
support to Tan's desired verdict. However, the reasoning makes appeal to a conception of institutional influence that is distinct from C2. The reasoning implies that an institution's imposition of policies regulating people's relative enjoyment of some good is equivalent to an institution's failure to adopt policies that would do the same. That is, both what an institution does and that which it refrains from doing qualify as ways in which it exerts impact over a distribution of goods. In this respect, this conception of institutional influence is broader than $\mathrm{C} 2$. On C2, only those distributive shares that an institution's rules actually do regulate qualify as institutionally influenced. On this more expansive conception, however, an institutional arrangement produces an inequality if and only if its regulation of, or its failure to regulate, the distribution of some good results in some individuals having a lesser share than others of the given good. Call the latter conception C3.14

But ILE-C3 will not do either, as it implies an implausibly broad range. As noted above, Tan is at pains to emphasize that there is a morally relevant difference between social disadvantages, which have an institutional input, and those disadvantages that are merely due to natural misfortune. He is clear that his theory allows for cases of natural misfortunes that society could address but need not as a matter of justice (2012: 127 and 142-44). For instance, he maintains that society need not provide corrective eyewear for the slightly shortsighted nor must it address all inequalities between the beautiful and ugly that are associated with their personal relationships. However, ILE-C3 implies otherwise. In the latter case, if a society could mitigate the disadvantages borne by the ugly by offering them publicly subsidized cosmetic surgery, then on ILE-C3 it must do so. This is because, on this conception, institutions must combat any morally arbitrary disadvantages that they are able to address. Within an institutional context, ILE-C3 appears to leave no room for the distinction Tan wishes to maintain between social disadvantages and merely natures ones: any natural contingency that an institution can address turns out to be social. So, ILE-C3 gives rise to implications that Tan rejects.

Setting aside C3, let us consider a different response to the charge that the range on ILE-C2 is implausibly narrow. To recall, the problematic verdict ILE-C2 appears to support, that unequal access to education is not unjust, was grounded in the observation that the society in question fails to regulate the provision of education. But, it might be pointed out, that assessment fails to take into account the fact that, by upholding the institutional apparatus needed to sustain a functioning market economy, this society regulates the distribution of economic opportunities between its members. And because society regulates this distribution, ILE-C2 implies that it would be unjust for some persons to enjoy superior economic opportunities to others based on contingent factors. Suppose that society's adoption of a system of universal

14 Tan's (2012: 35-38) discussion indicates support in some places for a conception like C2 and in others for a conception like $\mathrm{C} 3$. 
education would play a crucial role in reducing morally arbitrary inequalities in economic opportunities. In that case, then, ILE-C2 supports the verdict that this society ought to ensure that all citizens have access to a decent education, since doing so would be instrumental to reducing inequalities in economic opportunities.

This same reasoning seems to support Tan's verdicts in other cases. Arguably, social measures to ensure handicapped-accessible public spaces and to provide natural disaster relief are also instrumental to combating the emergence of luck-based inequalities in economic opportunities. In this way, one could argue that, on reflection, ILE-C2 avoids implying an implausibly narrow range. 15

However, now ILE-C2 confronts the opposite problem of implying an implausibly broad range. To see this, consider a variant of the river case discussed above. As before, suppose that two societies are settled along different parts of a river. Call them Upstream and Downstream. For many years, they live in complete isolation from one another. One day their paths cross, and they decide to establish a cross-society postal system to facilitate written communication between them. Let us suppose that the institution of the cross-society postal system gives rise to a benefit of which many citizens of the two societies avail themselves: having pen-pal relationships with foreigners. The pen-pal exchange turns out to be fulfilling for its participants. Meaningful friendships are forged, and participants benefit from this unique opportunity to learn about a different culture. Postal correspondence, however, is the extent of cross-society interaction, and otherwise the Upstreamers and Downstreamers continue to remain isolated.

It becomes apparent over time that some parties benefit more than others do from the postal system. Suppose that all Downstreamers have penpals, but only some Upstreamers do. The uneven participation of Upstreamers in the pen-pal exchange is due to a confidence gap within the Upstream society based on physical appearance. For years, before the two societies came into contact, those Upstreamers who happen to be blessed with good looks have been showered with praise by those around them, and consequently they are more confident than those Upstreamers who are homely. Based on this difference in confidence levels, the good-looking Upstreamers are more likely than their plainer-looking fellow citizens to sustain fulfilling pen-pal relationships with Downstreamers. Sadly, many homely Upstreamers receive no mail from Downstreamers, though they wish that they did. So, while those Upstreamers who are good-looking and all of the Downstreamers benefit from this cross-society institution, the ugly Upstreamers do not benefit from it at all.

ILE-C2 implies that this inequality is unjust. It does so based on the following line of reasoning. By establishing the postal system, the two societies have put into place an institutional arrangement that gives rise to a benefit

15 Some of Tan's remarks (2012: 44-47 and 104-5) suggest this reasoning. 
for their members - partaking in the pen-pal exchange - that did not exist before. Because the design of this institutional arrangement determines the extent to which different individuals who are subject to it will enjoy that benefit, on ILE-C2 it follows that the Upstreamers and Downstreamers must ensure that some of them do not enjoy a greater share of the benefit than others based on contingent factors. Consequently, it is unjust that the less good-looking Upstreamers do not benefit from this arrangement on a par with the others.

Consider the sorts of measures that may be called for to address this injustice. The Upstreamers and Downstreamers may be required to institute a cross-society redistributive scheme - perhaps by taxing postal supplies - and offer subsidized opportunities for cosmetic surgery or compensation to ugly Upstreamers. Alternatively, they might embark upon a cross-society campaign to challenge the prevailing norms of beauty in Upstream by, say, glorifying the likes of Shrek on stamps. Analogous cross-society demands of justice would arise to address any other contingencies that translate into lesser benefit from the postal system for some individuals. So, for instance, it would be unjust for some to receive less mail than others due to the misfortune of having bad penmanship or a poor memory for recalling zip codes.

Given the striking asymmetry between, on the one hand, the relatively minimal impact the postal system has on people's lives, and, on the other hand, the extensive demands of egalitarian justice posited, this seems to be the sort of verdict that Tan takes to be associated with an implausibly broad range. The postal system does nothing more than enable written communication between foreigners. Yet, on ILE-C2, Downstreamers (in addition to beautiful Upstreamers) could be required to make significant contributions to a redistributive scheme benefiting ugly Upstreamers simply because they belong to this common institution that facilitates the exchange of mail.

In response, Tan might deny that such cross-society demands of justice arise on ILE-C2 on the grounds that Downstreamers play no role in generating the ugly Upstreamers' disadvantage. Here he might point out that it is only members of Upstream, and not of Downstream, who are responsible for perpetuating the standards of beauty and associated social norms that result in the lower self-esteem of ugly Upstreamers. Because these problematic standards and norms that result in unequal benefit from the postal system are upheld within the confines of the Upstream society, Tan might argue that the demand to address this inequality, if it is an injustice at all, should be borne by Upstreamers alone rather than being a shared obligation of members of both societies.

But that response appeals to a factor that is irrelevant on ILE-C2. It is true that Downstreamers play no role in bringing about the diminished confidence of the ugly Upstreamers, which is a factor that crucially accounts for the morally arbitrary inequality in benefit from the postal system. Yet, in the cases discussed above of inequalities that are plausibly included in the range on ILE-C2, the ultimate source of an inequality is irrelevant. All that is rele- 
vant to establishing that an inequality is institutionally influenced is that an institution regulates the distribution of some good that is unevenly distributed. And if an institution plays this role, then it is unjust for some to enjoy greater distributive shares than others of the given good based on luck. So, for the sake of consistency, it appears that Tan is committed to the verdict that the imperative to remedy such inequalities is borne by both Upstreamers and Downstreamers.

Tan might claim that my argument concerning this case ignores a relevant factor. He might say that on ILE not just any institutional arrangement at all that regulates the distribution of goods gives rise to demands of egalitarian justice. Instead, he might take those demands to be activated only by institutions that fundamentally influence individuals' life prospects by defining and protecting their basic distributive entitlements. On this line, considerations of egalitarian justice arise in and only in the context of background rules and norms that determine people's basic distributive shares. This suggests a different conception of institutional influence, which we can call $C 4$. On C4, an institutional arrangement produces an inequality if and only if it regulates basic distributive entitlements, and with respect to those entitlements it grants some individuals a lesser share than others. ${ }^{16}$

It seems that on ILE-C4 the postal system would not suffice to activate demands of egalitarian justice since this institution merely facilitates the circulation of mail between Upstreamers and Downstreamers against a backdrop of preexisting distributive entitlements (as determined by the propertyrights schemes respectively imposed within the Upstream and Downstream societies). Thus, it appears that ILE-C4 might avoid the sort of implausible verdict generated on ILE-C2 - that extensive demands of justice arise in the face of institutions that seem to have very little impact on people's lives.

Since defining and enforcing property rights is a key way in which institutions can determine people's basic distributive shares, only inequalities in distributive holdings that are not subject to property rights protection between unequally situated parties will be excluded from the range on ILE-C4. However, the inequalities that Tan regards as plausibly falling outside of the range on ILE do not fall outside of the reach of such property rights protection. And so the inequalities he thinks should be excluded from the range for his theory to avoid an implausibly broad range are not excluded on ILE-C4.

To see this, consider the following case. Adele, who is beautiful, receives a diamond bracelet from one of her many admirers. Her fellow citizen, Beatrice, is not so lucky in the looks department. She has no admirers and never receives such extravagant gifts. Beatrice becomes envious of Adele - so envious that she steals the bracelet. The police find the bracelet in Beatrice's possession and return it to Adele, whom society recognizes as its rightful owner. In this case, society upholds Adele's property right to the greater

16 Tan's (2008: 684-87; 2012: 127 and 129-33) remarks seem to reflect support for a conception like $\mathrm{C} 4$. 
share of resources that she has, in part due to her beauty, and this right is enforced against others, such as Beatrice, who have less because they happen not to be as beautiful. Since this inequality in their distributive holdings is afforded institutional protection by their society's property rights scheme, it qualifies as institutionally influenced on C4. So, on ILE-C4, it is in the range. Yet the unequal distribution of jewelry between Adele and Beatrice seems to be precisely the sort of inequality that Tan thinks should be excluded from the range.

For the inequality between Adele and Beatrice to qualify as unjust on ILE-C4, they need not even belong to the same society. Suppose that Adele and Beatrice are citizens of different societies. Beatrice immigrates to Adele's society, and as before she is filled with envy and steals Adele's bracelet. Assuming that this society's property rights rules apply to immigrants within its borders, Beatrice would be liable to criminal charges for her theft of Adele's property, just as before. Alternatively, suppose that Beatrice is prevented from entering Adele's society based on its restrictive immigration policies. In this instance too, Adele's property right to the bracelet would be enforced against Beatrice, albeit indirectly: those who are barred from entering a society are thereby prevented from gaining access to the goods recognized as the property of those within that society's borders. Since in these cases, too, Adele's property right to the diamond bracelet would be afforded institutional protection against Beatrice, ILE-C4 again implies that the inequality between them is unjust.

Where there are background institutions that determine people's distributive entitlements, the reach of property rights protection tends to be extensive - so extensive that within those contexts virtually all distributive holdings seem to qualify as institutionally influenced on ILE-C4. Extrapolating from the cases just discussed, consider the real-world implications of ILE-C4. Since virtually all distributive holdings of individuals worldwide are subject to property rights protection, it is not clear which inequalities if any would fail to count as institutionally influenced on this construal of Tan's theory. ${ }^{17}$

Perhaps Tan could accept that his theory has this implication. He might try to deny its implausibility on the grounds that insofar as global rules and norms significantly and pervasively affect people's basic distributive shares, it seems correct upon reflection to regard these inequalities as unjust. Nevertheless, he might argue that, on $\mathrm{C} 4$, his theory still avoids the sort of troublesome verdicts associated with an implausibly broad range. This is because, he

17 Analogous reasoning to that employed in the bracelet inequality case suggests that the disadvantages associated with being slightly shortsighted and flat-footed would also be in the range on ILE-C4. Imagine that the shortsighted and flat-footed have less disposable income than their fortunate counterparts - those with naturally perfect eyesight and normal feet since they have to pay for such things as eyeglasses and arch supports. To the extent that institutional arrangements recognize persons without these minor impediments as being entitled to their slightly greater economic shares than the others, these inequalities, too, count as institutionally influenced and thereby unjust. 
might claim, some luck-based inequalities would not qualify as institutionally influenced on it and hence would be excluded from the range. So, for instance, if Adele did not have an enforceable property right in the bracelet that was upheld against Beatrice, then the inequality would not qualify as unjust. In the absence of an enforceable property right, Adele would merely possess the diamond bracelet, as in a state of nature, and Beatrice would be free to take it from her. Neither party then would be entitled to the bracelet. Only in such cases, in which distributive holdings fall outside the reach of a shared property rights scheme, would the inequality in bracelets between Adele and Beatrice fail to qualify as institutionally influenced.

Yet the cases that Tan discusses, in which some luck-based inequalities are excluded from the range on his theory, are not like those. The unlucky disadvantages that he points to do not concern distributive holdings that fall outside of the reach of property rights schemes - that is, holdings that have the status of state-of-nature possessions. His examples concern institutional contexts in which there are established property rights schemes. And under those institutional arrangements, it looks as though virtually all distributive holdings qualify as institutionally influenced on C4. So, ILE-C4 does not provide support for the verdicts that Tan needs in order to show that ILE avoids an implausibly broad range. 18

\section{Legitimate Expectations}

I have argued that ILE faces a dilemma. If the theory relies on a conception of institutional influence on which the range excludes inequalities that Tan thinks should be excluded, then it fails to include inequalities that he thinks should be included. If the theory relies on a conception of institutional influence on which the range includes inequalities that he thinks should be included, then it fails to exclude inequalities that he thinks should be excluded.

Tan might try to avoid the dilemma by invoking a factor that I have not mentioned. Suppose that ILE relies on a conception on which the range appears to be implausibly narrow, such as $\mathrm{C} 1$. An illustration of the problem I raised for ILE on that conception is that the range would fail to include the disadvantages suffered by victims of a hurricane. This is because the losses that some citizens endure at the hands of a natural disaster are, obviously, not brought about by any institutional intervention. Consider Tan's account

18 Tan might reply that he accepts the verdict that the inequality in bracelets between Adele and Beatrice is unjust in the context of a property rights scheme on the grounds that it does seem wrong intuitively for a society to allow luck-based discrepancies in the distributive entitlements that it determines. However, he might continue, the range on ILE would still exclude other looks-based inequalities that do not seem unjust, such as the beautiful being happier than the ugly. This reply does not circumvent the problem. This is because Tan (2012: 127) denies that ILE must depend on a resource-based rather than a welfare-based account of the currency of egalitarian justice to avoid giving rise to an implausibly broad range. 
of how ILE avoids that counterintuitive result. As he sees it, a society's failure to respond to the plight of hurricane victims would be "an institutional injustice because members of a society have the legitimate expectation that the state respond adequately within reason to such events" (2008: 681, n. 28). That this inequality is unjust seems to be explained at least in part, then, by people's expectations about what they are owed. Tan also makes appeal to this sort of explanation to show how ILE avoids an implausibly broad range, as it appears to face on C4. In the case of a flat-footed person who experiences minor discomfort associated with her condition, he says, "it is not contrary to common sense that she is expected to bear this small cost" (2012: 143, n. 17). So, by appeal to "expectations" concerning what individuals are owed by society, Tan might claim that ILE manages to avoid an implausibly narrow or implausibly broad range.

This response is inadequate. Obviously, Tan is not here referring to the actual expectations people happen to have, which might be ignorant or repugnant and have no bearing on the demands of justice. More plausibly, only some expectations would count as legitimate. Maybe Tan construes of legitimate expectations in the same way that Rawls does. For Rawls (1999: 273-75; 2001: 51-52 and 72-73), individuals' expectations are legitimate when they map onto their entitlements as defined by his theory of justice. ${ }^{19}$ That is, people may legitimately expect that which they are owed, which is independently justified. Tan, however, cannot help himself to this sort of explanation. If individuals' legitimate expectations were determined by and thus coextensive with their entitlements as specified by ILE, then appealing to these expectations would do nothing to adjust the problematic verdicts that the theory appears to imply. Such appeal would supply no additional conceptual resources beyond the luck/choice principle and whichever conception of institutional influence is adopted to change which inequalities fall in the range.

The device of legitimate expectations can enable adjustments in verdicts only if it is grounded in an independent normative principle that provides a basis for determining which expectations concerning entitlements are legitimate. Suppose that ILE allows for a normative principle alongside the luck/choice principle that does not derive from it. If neither principle has priority over the other, then the principles can clash in their recommendations, leading to irresolvable conflicts. However, if the other principle has priority over the luck/choice principle, this too would be problematic. As Tan puts it, "The significance and distinctiveness of luck egalitarianism as an account of equality is eliminated, if ... in the domain of distributive justice, the luck/choice principle is defeasible" (2008: 679, n. 25). So even if ILE could avoid the problematic implications raised in the last section by relying on an independent normative principle, this move is not available to Tan. This is because doing so would compromise the primacy of the luck/choice principle, thereby undermining ILE's luck-egalitarian character.

19 Tan (2012: 24) appears to endorse this Rawlsian understanding of legitimate expectations. 


\section{Conclusion}

Tan takes ILE to account for why (1) the unjust nature of certain inequalities seems to be explained by their source in luck, while (2) not all inequalities that stem from luck seem unjust. In his view, accounting for (1) gives ILE an advantage over democratic equality, and accounting for (2) gives ILE an advantage over TILE.

However, accounting for (1) and (2), as we have seen, requires showing that the range on ILE is plausible given the verdicts it supports in particular cases. And I have argued that showing this faces substantial, and arguably insurmountable, obstacles. ILE depends on the concept of institutional influence, which Tan does not explain sufficiently. On reflection, it appears that, however this concept is construed, the range on ILE is either implausibly narrow or implausibly broad. That the theory initially appears to account for (1) and (2) may be due to an equivocation between different conceptions of institutional influence. As far as I can see, to resist my argument Tan would have to invoke a normative principle that is not derivable from the luck/choice principle, thus sacrificing the primacy of the luck/choice principle in the domain of distributive justice.

Tan appears to be left with three options. He can accept what he regards as an implausibly narrow range; accept what he regards as an implausibly broad range; or give up on the primacy of the luck/choice principle. It seems to me that only the latter two options are viable. This is because it is unclear what value there would be in preserving the theory's luck-egalitarian character - by upholding the primacy of the luck/choice principle - if that theory cannot account for the unjust nature of precisely the sorts of luck-based inequalities that motivate the luck-egalitarian project. ${ }^{20}$ So, if Tan wishes to defend a luck-egalitarian theory, it looks like he is committed to what he regards as an implausibly broad range. But that commitment would undermine the advantage he claims for ILE over TILE. And as Tan sees it, for a theory to imply the sorts of verdicts associated with an implausibly broad range, as trans-institutional approaches do, "would fatally convict luck egalitarianism of absurdity" (2012: 144; see also 126-28 and 143-44). The alternative is giving up on primacy, but that amounts to giving up on luck egalitarianism. ${ }^{21}$ In

${ }^{20}$ In fact, Tan (2012: 142-44) acknowledges that his theory may imply some verdicts associated with an implausibly narrow range, and he accepts that implication as a price that must be paid for ILE's avoidance of what he regards as the more problematic implication of an implausibly broad range. However, on a conception like $\mathrm{C} 1$ that implies an implausibly narrow range, the problem is not that ILE yields counterintuitive verdicts in a handful of cases. Rather, the problem is pervasive: ILE on such a conception fails to account for the unjust nature of inequalities that are central to demonstrating the intuitive appeal of luck egalitarianism.

${ }^{21}$ Notwithstanding Tan's explicit claims to the contrary, that ILE may rely on a foundational normative principle other than the luck/choice principle is suggested by his (2012: 79 and 159) appeals to the value of reciprocity in justifying the demands of ILE. So, perhaps ILE 
any case, if my arguments are sound, then the merits of an institutional version of luck egalitarianism are dubious. 22

Rekha Nath

University of Alabama

Department of Philosophy

rekha.nath@ua.edu

turns out to bear greater resemblance to a version of democratic equality than Tan recognizes.

22 I am very grateful to Torin Alter for numerous helpful conversations and written comments, as well as to two anonymous referees for the Journal of Ethics \& Social Philosophy for their detailed suggestions for improvement. I benefited from the opportunity to present an earlier version of this paper at the Australian National University. Work on this paper was supported by an RGC grant from the University of Alabama. 


\section{References}

Anderson, E. (1999) "What Is the Point of Equality? Ethics 109: 287-337.

Arneson, R. J. (2000) "Luck Egalitarianism and Prioritarianism," Ethics 110: 339-49.

Freeman, S. (2007) Justice and the Social Contract, New York: Oxford University Press.

Rawls, J. (2001) Justice as Fairness: A Restatement, E. Kelly, ed., Cambridge, Mass.: Harvard.

(1999) A Theory of Justice, revised edition, Cambridge, Mass.: Harvard University Press.

Tan, K. C. (2012) Justice, Institutions, and Luck: The Site, Ground, and Scope of Equality, Oxford: Oxford University Press.

(2011) "Luck, Institutions, and Global Distributive Justice: A Defence of Global Luck Egalitarianism," European Journal of Political Theory 10: 394-421.

(2008) "A Defense of Luck Egalitarianism," The Journal of Philosophy 105: 665-90. 